\title{
Gyrochorte "highways" and their environmental significance in shallow-marine sediments
}

Andreas Wetzel, Noelia B. Carmona, and Juan J. Ponce

Acta Palaeontologica Polonica 65 (1), 2020: 209-218 doi:https://doi.org/10.4202/app.00655.2019

The reworking of a trace by a subsequently following organism represents a so-called sequorichnial behavior and leads to formation of a "burrowing highway". Burrowing highways occur more frequently than assumed in the fossil record. Their ichnological and sedimentological meaning is elucidated by using the trace fossil Gyrochorte. Gyrochorte producers exploiting sandy event beds tend to use "burrowing highways" in the same direction. Evidently, the Gyrochorte producers are thigmotactically highly sensitive as they can recognize a burrow produced by the same species because of the less densely packed grains, a somewhat increased mud content, and supposedly mucus segregated within the burrow. These changes make the reworking of pre-existing burrows energetically advantageous. However, in shallow-marine settings mucus is degraded rapidly and loose sediment consolidates in a short while. Therefore, the time to recognize a pre-existing burrow appears to be limited and a rather high number of organisms is a prerequisite for reutilization of a previous trace. "Burrow highways" potentially represent an additional criterion to characterize an opportunistic population strategy.

Key words: Polychaete, ichnology, behaviour, sequorichnia, Cretaceous, Argentina.

Andreas Wetzel [andreas.wetzel@unibas.ch], Departement Umweltwissenschaften, Geologie, Universität Basel, Bernoullistrasse 32, CH-4056 Basel, Switzerland. Noelia B. Carmona [ncarmona@unrn.edu.ar] and Juan J. Ponce [jponce@unrn.edu.ar], CONICET, Instituto de Investigación en Paleobiología y Geología, Universidad Nacional de Río Negro, General Roca. 8332, Rio Negro, Argentina.

This is an open-access article distributed under the terms of the Creative Commons Attribution License (for details please see creativecommons.org), which permits unrestricted use, distribution, and reproduction in any medium, provided the original author and source are credited. 
PaF Full text $(1,400.2 \mathrm{kB})$ 